\title{
Reflexiones sobre los BIC conjuntos históricos: la Sierra de Cádiz
}

\author{
María Teresa Pérez Cano | Dpto. Urbanística y Ordenación del Territorio, Universidad \\ de Sevilla
}

URL de la contribución <www.iaph.es/revistaph/index.php/revistaph/article/view/3761>

\section{RESUMEN}

La tipología de inmuebles BIC conjunto histórico es la estrategia usada para salvaguardar los valores de las "unidades de asentamientos". Valores sobre los que cabe reflexionar, ya que al referirnos a construcciones urbanas 0 rurales debemos de entender que hablamos fundamentalmente de valores urbanísticos, paisajísticos y territoriales. Aunque en su formulación se recojan expresamente por "su interés histórico, arqueológico, paleontológico, artístico, etnológico, industrial, científico, social o técnico". Aspectos compartidos con otras tipologías de bienes inmuebles, especialmente con la de monumento, pero que dejan fuera expresiones como "formas de vida, cultura, actividades y modos de producción" asociadas a lugares de interés etnológico o "vinculados a modos de extracción, producción, comercialización, transporte o equipamiento" (LEY 14/2007: art. 26, tít. III), referidas a lugares de interés industrial. Para finalmente referirse exclusivamente al "valor de uso y disfrute para la colectividad y, en su caso, valores paisajísticos y ambientales, cuando define las zonas patrimoniales, añadiendo la idea de conjunto patrimonial, diverso y complementario" (LEY 16/1985: art. 15, tít. II).

Evidentemente lo patrimonial es complejo, pero esa literalidad de valores o limitación conceptual entre monumento y conjunto histórico hace que a veces se confundan, elevando lo arquitectónico al principal papel protagonista y diferenciándose principalmente en lo referido a su condición de lugar, esto es, "accidentes geográficos o estructura física representativa". Esta aportación, tomando como fondo los conjuntos históricos declarados de la Sierra de Cádiz, trata de analizar si estas declaraciones cumplen sus objetivos iniciales. Así mismo se intentará poner de manifiesto si las otras poblaciones que integran la sierra, serian merecedoras o no, de dicha protección.

\section{Palabras clave}

Bien de interés cultural | Cádiz (Provincia) | Conjuntos históricos | Sierra de Cádiz | Valores urbanísticos | 


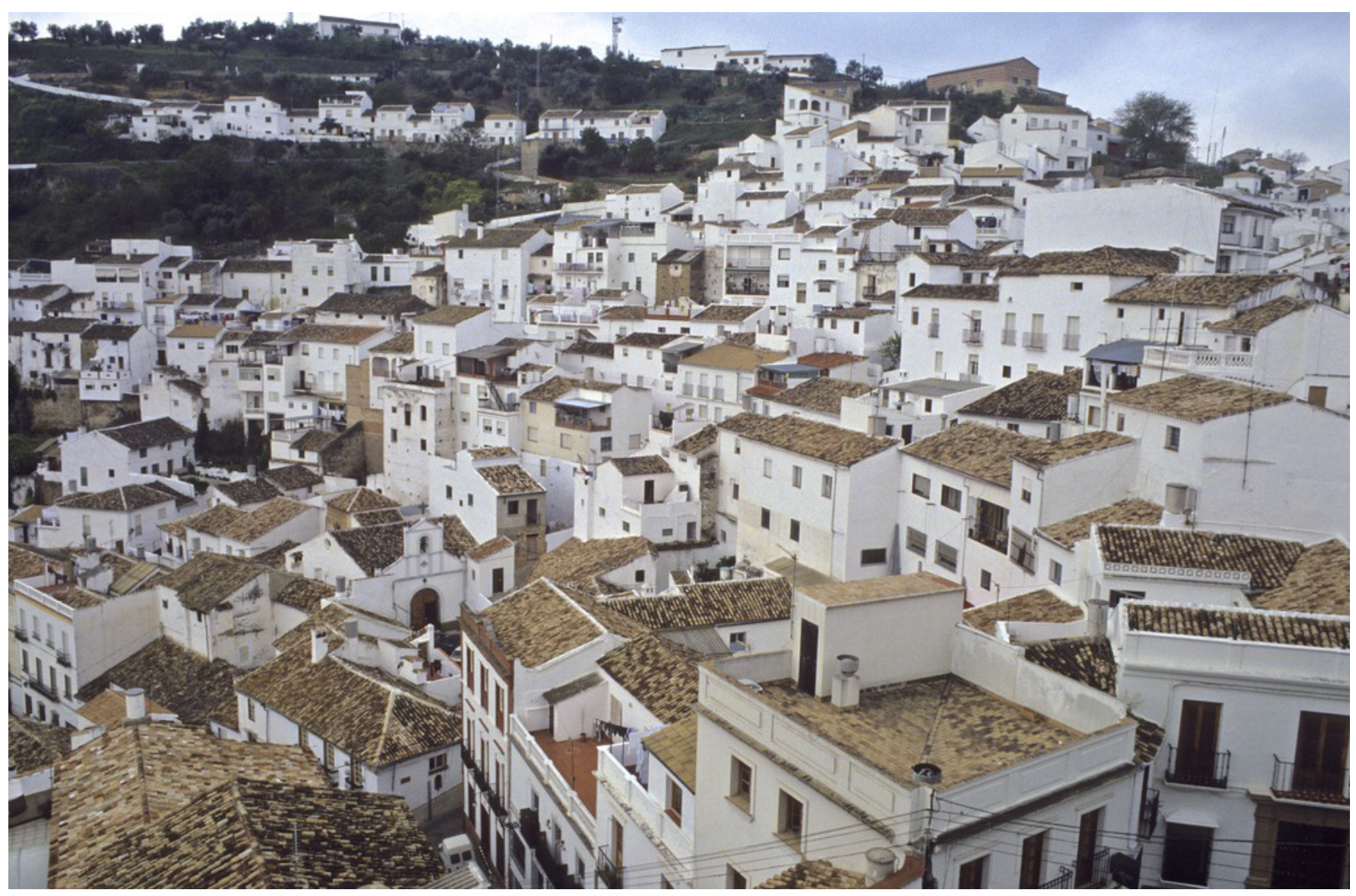

Ciudad histórica de Setenil de las Bodegas | foto Fondo Gráfico IAPH (Isabel Dugo Cobacho) 
1

Conjunto Histórico, en adelante $\mathrm{CH}$
1. Situación de la Sierra de Cádiz en el contexto de su provincia | elaboración propia (Clara Mosquera Pérez y María Teresa Pérez Cano) a partir de plano base de Cartoetsa. De todas las imágenes que ilustran este texto si no se indica lo contrario, en todas o alguna de las partes
El trabajo que se presenta al lector tiene como tema de estudio la Sierra de Cádiz y como objeto del mismo, sus conjuntos históricos. El objetivo principal es verificar si la declaración administrativa de estos bienes inmuebles como conjuntos históricos se ha hecho atendiendo a todo el potencial que tiene esta tipología patrimonial, o responde a una visión reducida de la misma, como respuesta a una valoración fundamentalmente arquitectónica.

La evolución en estos años en materia de patrimonio cultural pone a nuestro entender de manifiesto la limitación conceptual con la que desde sus inicios se concibió y definió la tipología de inmueble conjunto histórico. Bien es sabido que se pasó del edificio aislado a la ciudad, pensando siempre en claves de lo construido, del jardín a la catalogación urbanística del espacio público, incluso al ambiente urbano, incluyendo desde 1985 la idea de entorno. Pero podíamos preguntarnos si estos sumatorios de visiones parciales nos transmiten esa idea de ciudad completa, en todas sus complejidades y matices, a nivel individual como hecho urbano, y también formando parte de un sistema superior con capacidades de estratificar, jerarquizar y ordenar ámbitos territoriales tan distintos. Pensamos que esta visión más holística no ha sido tenida en cuanta en la definición de conjunto histórico ${ }^{1}$, y la Sierra de Cádiz es buen ejemplo de ello.

La provincia de Cádiz alberga un amplio territorio con paisajes diferentes que señalan su diversidad cultural. De sus cuarenta y cuatro municipios actua-

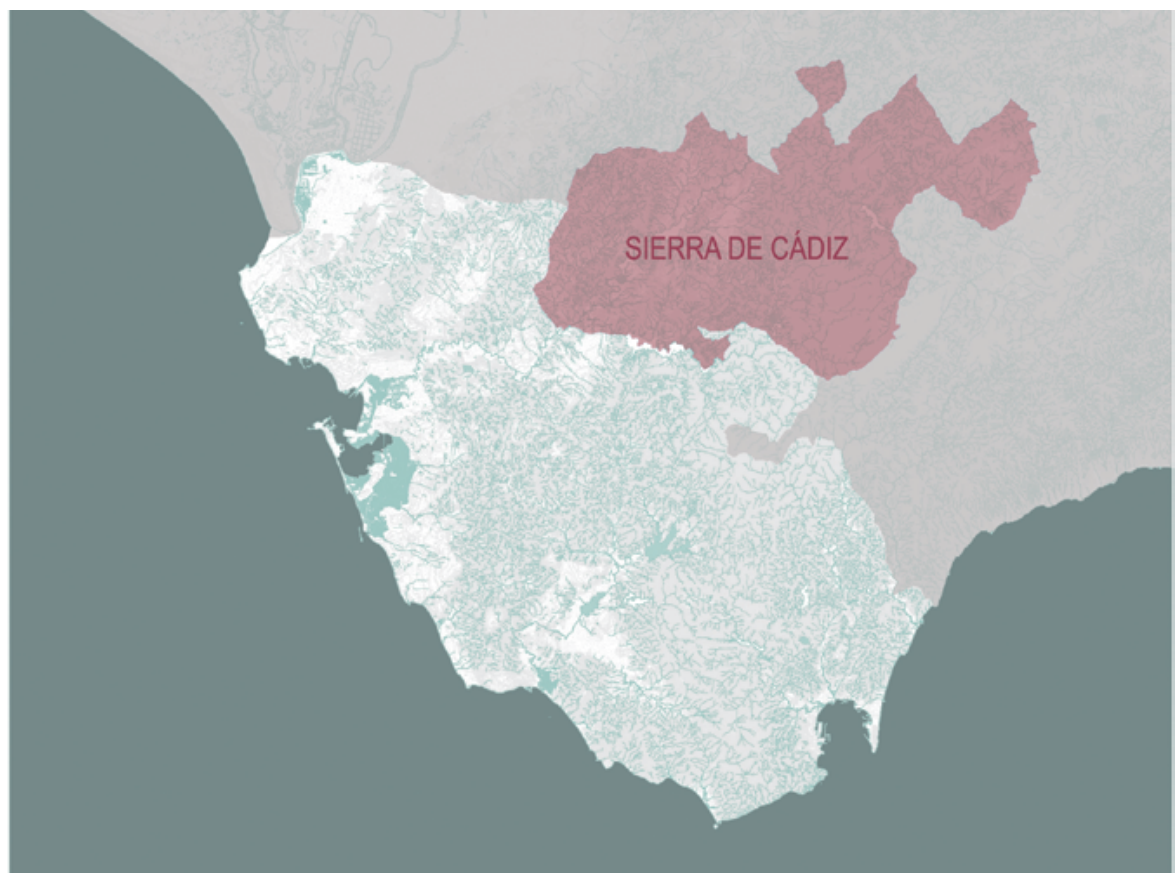


les, veintiséis son conjuntos históricos declarados. La conformación de la misma en el tiempo y en el espacio ha determinado su división administrativa actual en las denominadas comarcas: Litoral², Campiña, La Janda, Campo de Gibraltar y Sierra de Cádiz. Pero esta situación históricamente no ha sido siempre la misma, lo que deriva en escenarios urbanos distintos que nos señalan y explican la complejidad de este espacio secular.

De los cuarenta y cuatro municipios que en la actualidad componen la provincia, diecinueve ${ }^{3}$ (un 43,18\%) integran la Sierra de Cádiz y diez de ellos son conjunto histórico. Si los analizamos desde el punto de vista de la superficie que ocupa cada término municipal, vemos que ese porcentaje se concentra en algo menos del veintisiete por ciento del total de la provincia, exactamente el $26,85 \%$, lo que nos señala una de las características más relevantes de este territorio (planos 1 y 2 ).

Una comarca formada en su mayoría por pequeños municipios, donde el $\mathrm{CH}$ de Arcos de la Frontera, con un 7,09\%, de la superficie es la excepción ${ }^{4}$. En un siguiente escalón aparecen dos municipios: Villamartín $(2,85 \%)$ y el $\mathrm{CH}$ de Olvera (2,60\%); y, un poco más abajo, los $\mathrm{CH}$ de Algodonales $(1,80 \%)$, Espera $(1,66 \%)$ y Grazalema $(1,65 \%)$. El resto de los doce municipios restantes se deslizan entre el $0,36 \%$ del más pequeño, Algar, y el $1,11 \%$ del $\mathrm{CH}$ de Setenil de las Bodegas. De estos seis municipios mayores, un alto porcentaje, cuatro, es conjunto histórico. No es casual que a mayor tamaño, más protagonismo territorial.

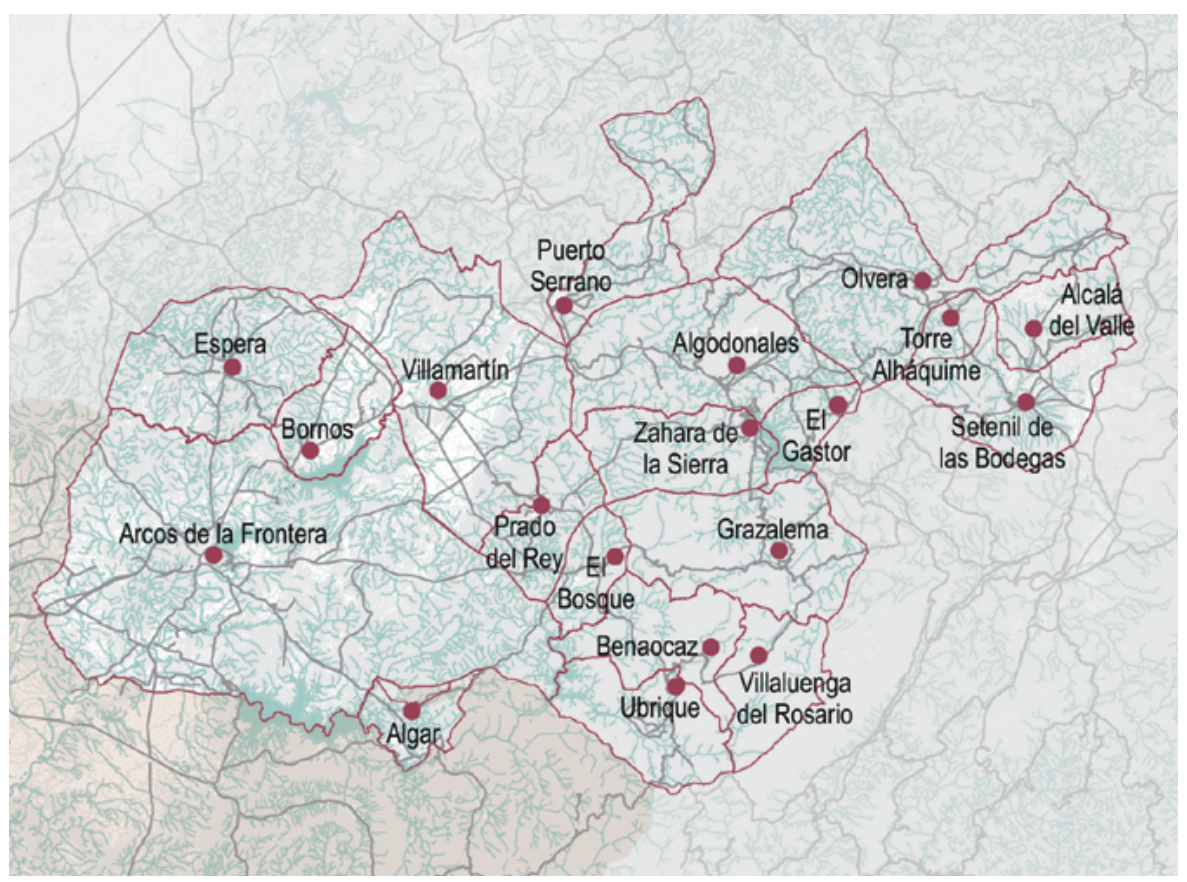

2

Aunque algunos historiadores como Juan Ramón Cirici Narváez o Alberto Ramos Santana, diferencian en la comarca Litoral dos sectores: Bajo Guadalquivir y Bahía de Cádiz. Ver La Provincia de Cádiz, Pueblo a Pueblo (AA. VV., 2000).

3

Por orden alfabético son: Alcalá del Valle, Algar, Algodonales $(\mathrm{CH})$, Arcos de la Frontera $(\mathrm{CH})$, Benamahoma, Benaocaz $(\mathrm{CH})$, Bornos $(\mathrm{CH})$, El Bosque, El Gastor, Espera, Grazalema $(\mathrm{CH})$, Olvera $(\mathrm{CH})$, Prado del Rey, Puerto Serrano, Setenil de las Bodegas $(\mathrm{CH})$, Torre Alhamique $(\mathrm{CH})$, Ubrique $(\mathrm{CH})$, Villaluenga del Rosario, Villamartín y Zahara de la Sierra $(\mathrm{CH})$.

4

Fuente: SIMA, Instituto de Estadística y Cartografía de Andalucía. 
Pero también cabría otra interpretación: ser un municipio de pequeña superficie puede indicarnos lo disputado que puede llegar a ser un territorio. Vaivén de fronteras, mostrar su capacidad de acogida de población a lo largo de los siglos..., características muy relevantes si hablamos de un territorio antropizado susceptible de ser patrimonializado.

Si tomamos el parcelario catastral urbano como referencia y sus relaciones morfotipológicas, autentico ADN de cada ciudad, podemos identificar los fragmentos de la misma con parcelarios más menudos, con los sectores más antiguos de la urbe, marcadamente funcionarizados, históricamente plenos de actividad. Ello ha condicionado el valor del suelo, por lo que, fruto de la tensión económica, el espacio se ha ido subdividiendo, afectando al parcelario e incluso al tamaño de las manzanas. Por contra, grandes parcelas en sectores de grandes manzanas, nos hablan de continuidad en la propiedad, de estabilidad funcional, de congelación de actividades e incluso de menor densidad de población. Situaciones intermedias, sea el caso del $\mathrm{CH}$ de Torre Alhamique, de homogeneidad morfológica y catastral, señalan la estabilidad en el tiempo y en el espacio de esta "unidad de asentamiento" (plano 3).

3. Delimitación del conjunto histórico de Torre Alháquime. Véase la forma de las manzanas y la configuración y tamaño de las parcelas | elaboración propia a partir del plano base: Decreto 70/2003, de 11 de marzo

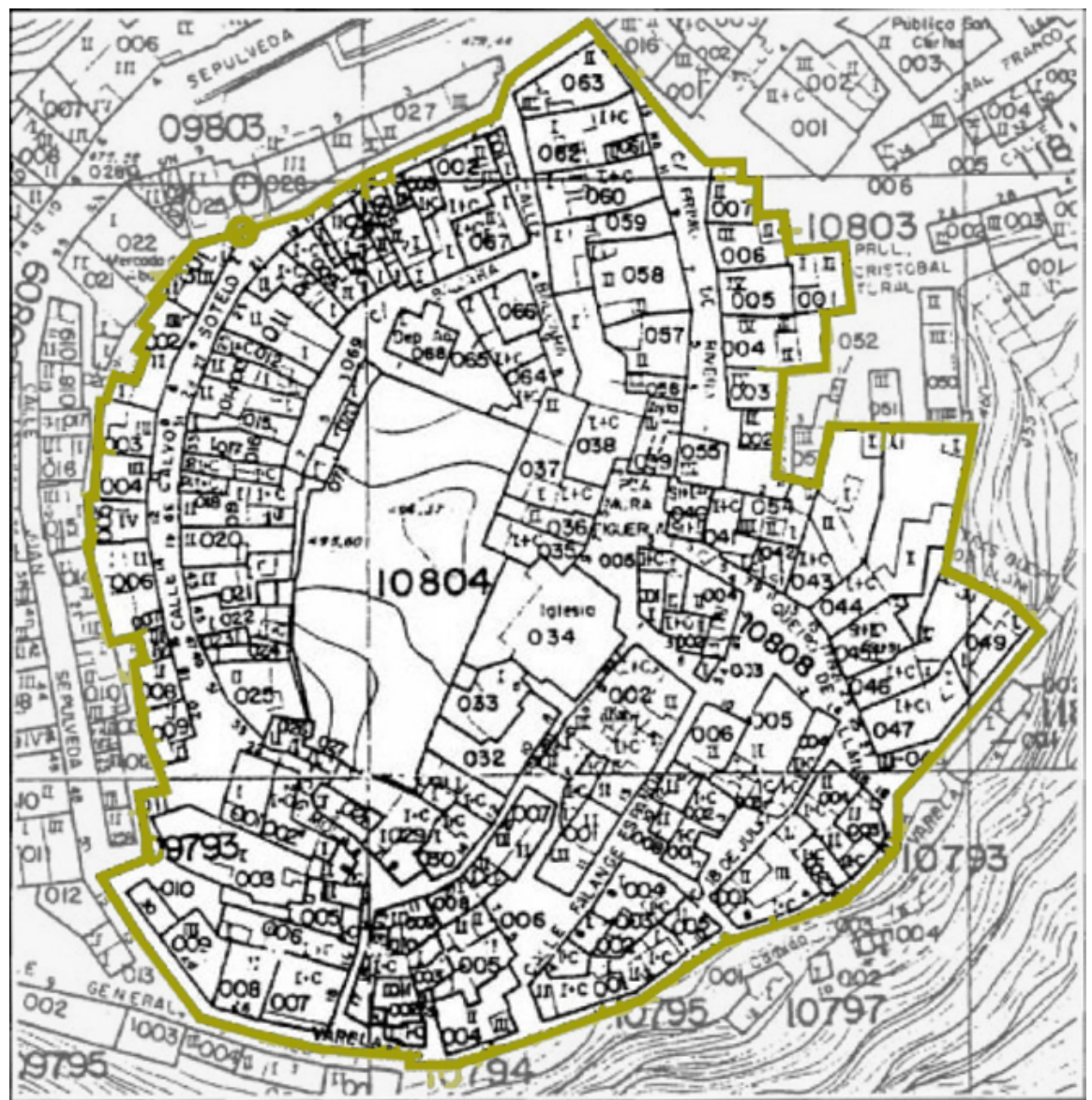



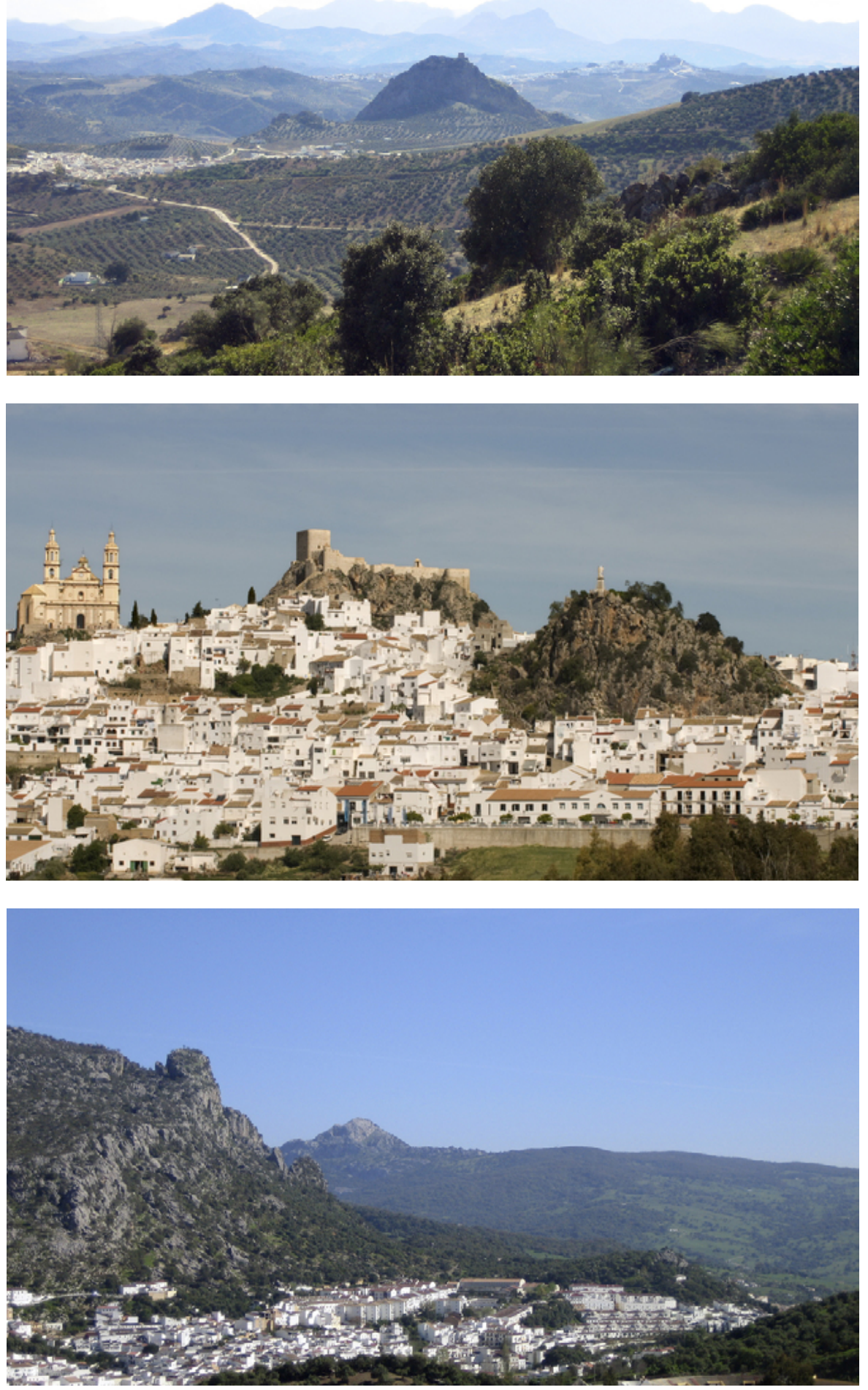

Ciudad Histórica de Zahara (110420044) | foto Fondo Gráfico IAPH (Esther López Martín)

Vista panorámica de Olvera (Cádiz) | foto Fondo Gráfico IAPH (Juan Carlos Cazalla Montijano)

Ciudad histórica de Ubrique | foto Fondo Gráfico IAPH (Esther López Martín) 
5

Plan de Ordenación del Territorio de Andalucía, aprobado por Decreto 206/2006 de 28 de noviembre.

\section{6}

Datos referidos a 2015. Fuente: SIMA, Instituto de Estadística y Cartografía de Andalucía.
Del Modelo Territorial de Andalucía recogido en el Plan de Ordenación del Territorio $^{5}$ (POTA), destacamos que nuestra comarca se encuentra entre los dominios territoriales del valle del Guadalquivir: Arcos, Bornos, Villamartín y Puerto Serrano; y el de las sierras y valles béticos: Prado del Rey, Ubrique, Algodonales, Olvera y Alcalá del Valle. Vemos que solo son nombrados por sus topónimos 9 de los 19 municipios, los que integran la red de ciudades medias de la comarca, siguiendo la jerarquía establecida en su sistema de ciudades, que deja fuera los asentamientos cuya población no supera los cinco mil habitantes.

En el caso que nos ocupa tenemos dos ciudades medias de segundo orden que actúan como cabeceras de la red: Arcos de la Frontera y Ubrique, ambas conjuntos históricos declarados; y otras dos: Villamartín y Olvera, esta última conjunto histórico, actuando como centro rural o pequeña ciudad 1, respectivamente. Las cinco restantes, Bornos, Puerto Serrano, Prado del Rey, Algodonales y Alcalá del Valle, lo hacen como centros rurales o pequeñas ciudades 2. De esta última serie, solo Algodonales es conjunto histórico (plano 4).

La población de la Sierra de Cádiz representa una de las densidades menores de entre las comarcas gaditanas, situándose en torno al 9,56\% sobre el total provincial ${ }^{6}$. Solo Arcos de la Frontera, con un $2,52 \%$, supera los treinta y un mil habitantes, ocupando el puesto número 10 de las ciudades más pobladas de la provincia. Le sigue a continuación Ubrique $(1,36 \%)$ con algo más de la mitad de población que el municipio anterior, aunque ya en el puesto número 18 del total provincial. Villamartín en el puesto 20 , con un $0,99 \%$, es el tercero de los municipios de la sierra, que se encuentra por encima de la media provincial.

Pero debemos señalar como rasgo más definitorio de esta comarca, en cuanto a población se refiere, que de los 44 municipios que componen la provincia gaditana, si los ordenamos por tamaño de población, encontramos que los 9 últimos de la lista, los menos poblados, pertenecen a la comarca de la Sierra de Cádiz. Cinco de los cuales son conjuntos históricos: Setenil de las Bodegas (0,23\%), Grazalema $(0,17 \%)$, Zahara de la Sierra $(0,12 \%)$, Torre Alháquime y Benaocaz, ambos con un $0,06 \%$ de la población provincial. Villaluenga del Rosario, con 471 habitantes (0,04\%) ocupa el último puesto de la lista. En definitiva, nos encontramos por tanto con una comarca que agrupa el $43,18 \%$ de los municipios de la provincia, en un $26,85 \%$ de superficie, con un $9,56 \%$ de población.

Si tomamos como referencia, la zonificación del POTA y sus unidades territoriales vemos que aparecen parcialmente agrupadas en la misma unidad territorial, dos provincias, Cádiz y Málaga, mediante la denominada serranías de Cádiz y Ronda. Son tres los conjuntos históricos que actúan como 


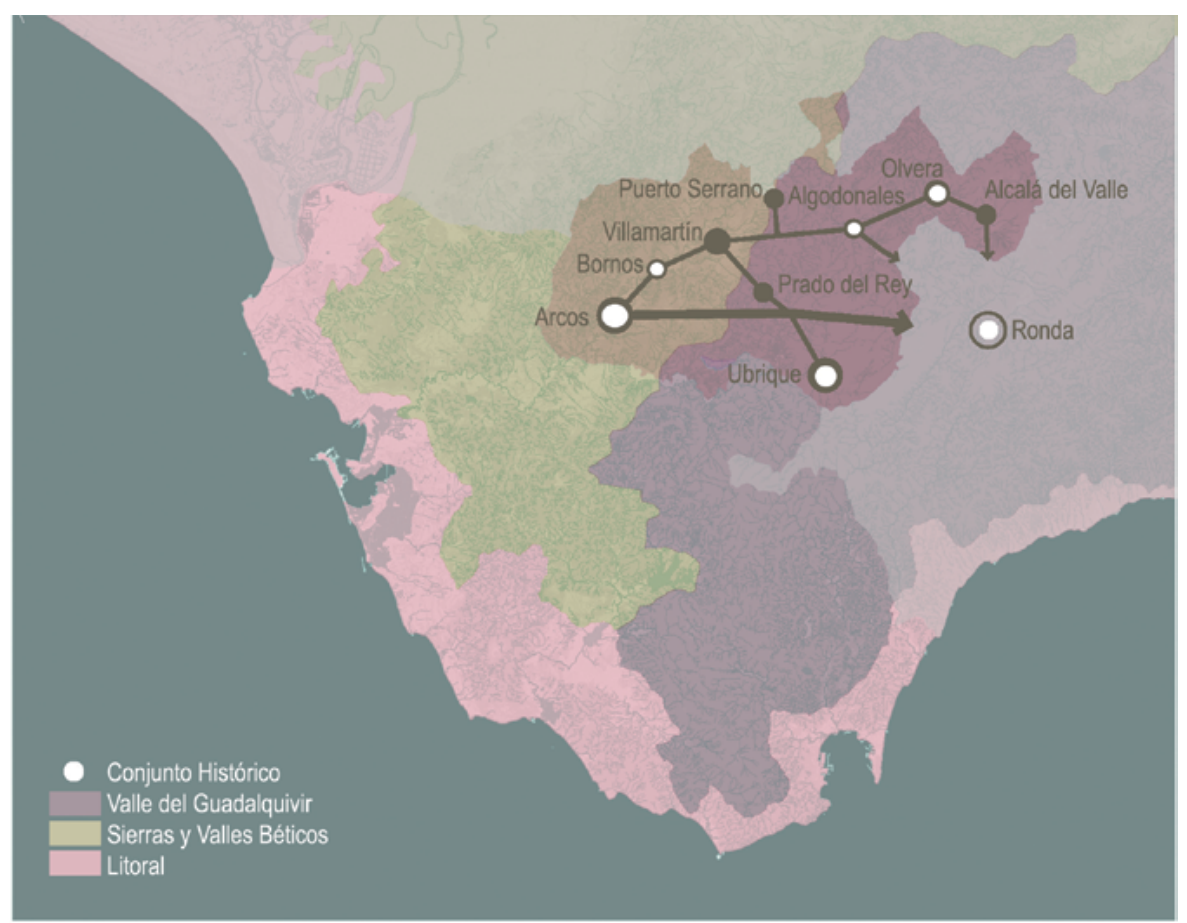

4. Concreción del Sistema de Ciudades de Andalucía en la Sierra de Cádiz | plano elaboración propia a partir del Modelo Territorial de Andalucía (POTA)

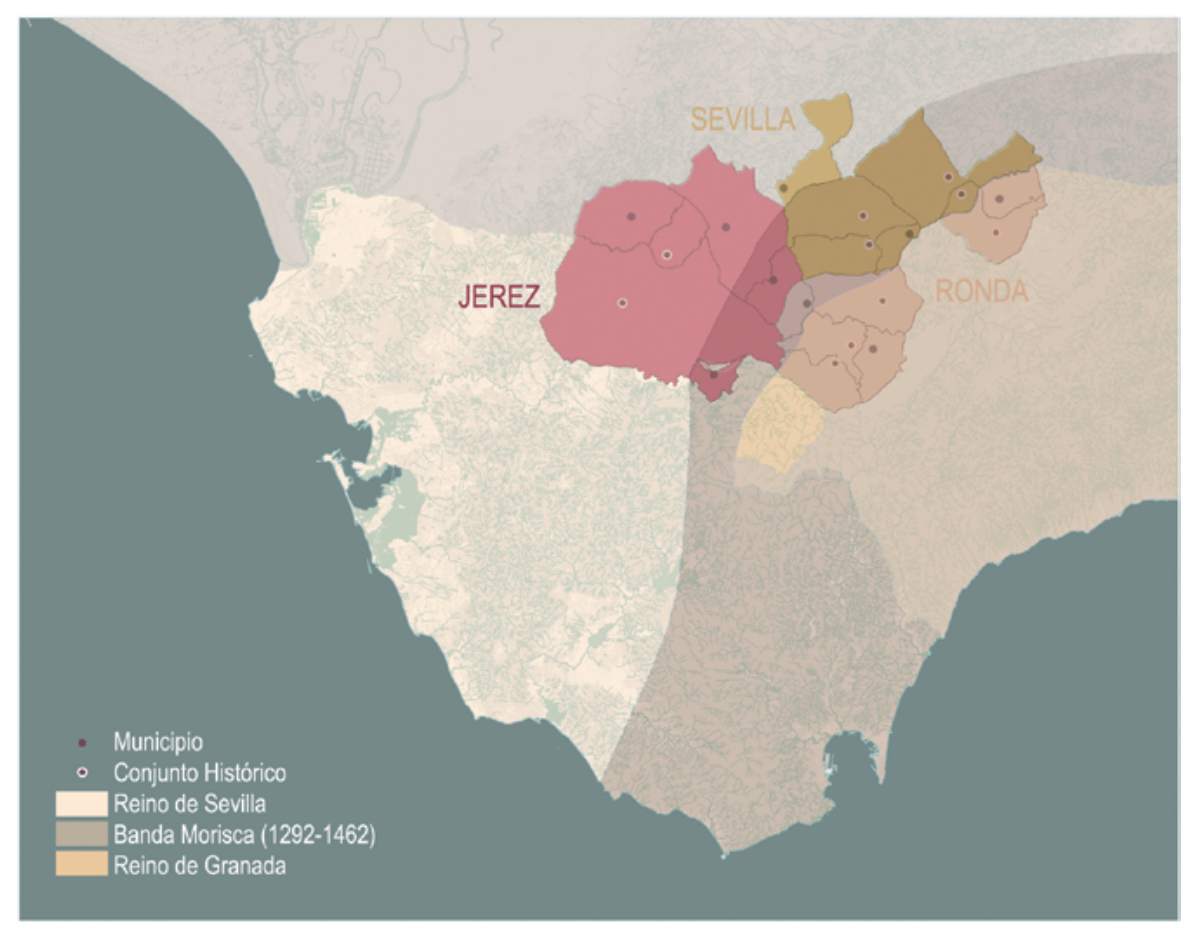

5. La importancia del espacio frontera entre el Reino de Sevilla y el Reino de Granada en la configuración de los conjuntos históricos de la Sierra de Cádiz. Se identifica en colores diferentes la procedencia según los históricos partidos judiciales de Jerez, Sevilla y Ronda 
7

Según el Catastro de Ensenada de 1749, Alcalá del Valle, Benaocaz, Grazalema, Setenil, Ubrique y Villaluenga del Rosario formaban parte de la provincia de Granada. Se puede consultar en el Catastro de Ensenada [en línea] <http://pares.mcu.es/Catastro/servlets/ ServletController> [Consulta: 22/2/2016].

\section{8}

El Reino de Sevilla se dividía en Cádiz, Campo de Gibraltar, Jerez de la Frontera, Sanlúcar de Barrameda y Sevilla. Ronda pertenecía al Reino de Granada. centros: Arcos de la Frontera, Ubrique y Ronda. Aunque el mayor protagonismo como ciudad media de primer orden lo asume Ronda, cuestión que tiene que ver con la trayectoria acontecida por estos municipios a lo largo de su historia.

Para situarnos, antes de la división provincial elaborada en tiempos de Carlos III por el conde de Floridablanca en 1789 (MADOZ, 1986: 63), la provincia de Cádiz procedía de los antiguos Reinos de Sevilla y Granada, siendo, sin duda, la Sierra de Cádiz el sector que más claramente compartía esta dualidad de orígenes ${ }^{7}$. Así mismo la división de los dos reinos en partidos provinciales nos sitúa en un espacio territorial fragmentado entre los ámbitos a los que pertenecían: Ronda, Jerez y Sevilla ${ }^{8}$. De los diecinueve municipios que constituyen la Sierra de Cádiz, formaban parte del partido de Ronda: Alcalá del Valle, Benaocaz, El Bosque, Grazalema, Setenil de las Bodegas, Ubrique, Villaluenga del Rosario. Del partido de Jerez: Algar, Arcos de la frontera, Bornos, Espera, Prado del Rey, Villamartín. Y del partido de Sevilla: Algodonales, El Gastor, Olvera, Puerto Serrano, Torre Alháquime, Zahara de la Sierra (plano 5).

Veremos cómo esta división territorial ha marcado su origen y destino como futuros conjuntos históricos. No debemos de olvidar que el proceso de cristianización, con diferencias de más de dos siglos en las conquistas de sus poblaciones, Arcos de la Frontera en el año 1264 y Alcalá del Valle 1484, han caracterizado el proceso de su poblamiento y posterior evolución.

Analizando las declaraciones comprobamos que de los siete municipios que procedían del antiguo partido judicial de Ronda, 4 son en la actualidad $\mathrm{CH}$. De los doce restantes integrados entre Jerez y Sevilla, la mitad son a día de hoy $\mathrm{CH}$. Pero cuáles son los valores señalados en la construcción de los "espesores patrimoniales" de los $\mathrm{CH}$ de la Sierra de Cádiz, que como capas de hojaldres nos ayudaran a entender su verdadero significado. Para responder a esta pregunta vemos necesario explicar cual ha sido la secuencia de su protección (plano 6).

El primer $\mathrm{CH}$ de la provincia de Cádiz en declarase fue Arcos de la Frontera en el año 1962, al amparo de la Ley de 13 de mayo de 1933 (LEY, 1933), por delante de ciudades como Jerez de la Frontera (1967), Sanlúcar de Barrameda (1972) o Cádiz capital (1973). Como sabemos, en esta primera etapa de la protección los valores histórico y artístico como elementos determinantes de la protección de un bien, serán los de mayor peso al declarar. Pasarán más de veinte años hasta que otros municipios se incorporen a la nómina de la protección (planos 7 y 8 ).

A lo largo de 1982, recién iniciada la andadura democrática y el estado de las autonomías, se incoan expedientes para la declaración de cinco muni- 

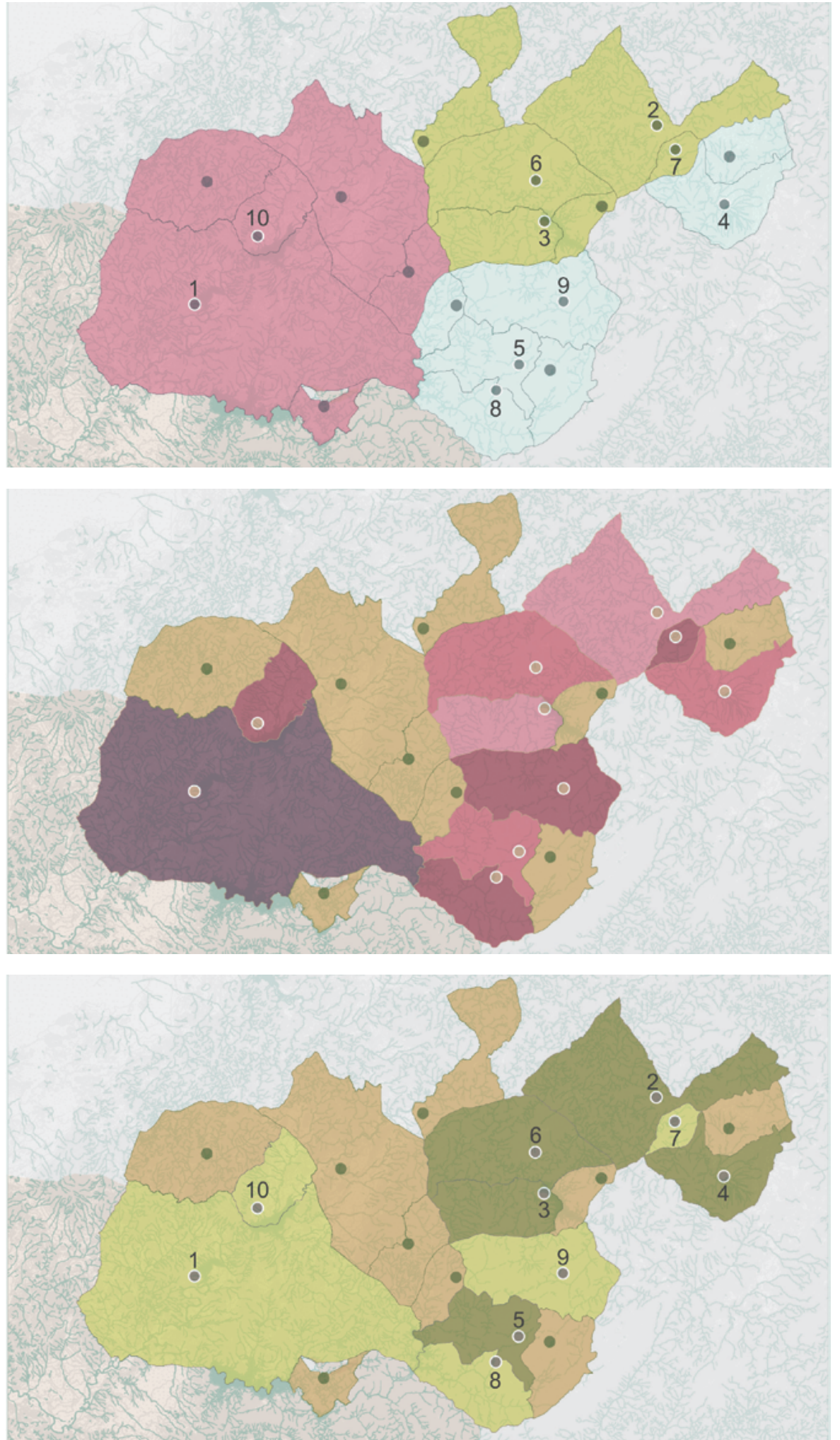

6. Secuencia en la declaración de los conjuntos históricos de la Sierra de Cádiz: 1. Arcos de la Frontera, 2. Olvera, 3. Zahara de la Sierra, 4. Setenil de las Bodegas, 5. Benaocaz, 6. Algodonales,7.

Ubrique, 9. Grazalema, 10. Bornos. Arcos de la Frontera ha ampliado en 2004 la delimitación de 1962. Se identifica en colores diferentes la procedencia según los históricos partidos judiciales de Jerez, Sevilla y Ronda

7. Zonificación por año de declaración, de los conjuntos históricos de la Sierra de Cádiz. En gama de rosas, de claro a oscuro: 1983, 1985, 2003 y 2004

8. Legislaciones de patrimonio vigentes en el momento de la declaración de los conjuntos históricos. Ley de 13 de mayo de 1933, en los casos de 2 Olvera, 3. Zahara de la Sierra, 4 . Setenil de las Bodegas, 5. Benaocaz, 6. Algodonales. Y Ley 16/1985 para los casos de 7. Ubrique, 9. Grazalema, 10. Bornos y 1 Arcos de la Frontera 
Puede consultarse cualquiera de los decretos cuyas fechas se ha señalado. cipios. Mediante informe aún de la Real Academia de Bellas Artes de San Fernando, y por decreto del entonces Ministro de Cultura Javier Solana se resuelven en 1983, aún como conjunto histórico-artístico, primero Olvera (13 de abril de 1983) y Zahara de la Sierra (20 de octubre de 1983). Dos años después, aún al amparo de la Ley de 13 de mayo del 1933, pero ya siendo Consejero de Cultura, Javier Torres Vela, se terminan los expedientes de Setenil de las Bodegas (22 de enero de 1985), Benaocaz (5 de febrero de 1985) y Algodonales (2 de mayo de 1985). Son decretos breves, donde solo se argumenta siempre con el mismo texto que "el citado conjunto reúne los méritos suficientes para merecer dicha declaración"9.

La Ley 16/1985 de Patrimonio Histórico Español, cambia este panorama, introduciendo una amplia panoplia de valores que se sumarán a los ya tradicionales. Situación que se mantiene, en materia de $\mathrm{CH}$, en las sucesivas leyes de patrimonio de Andalucía (LEY 1/1991; LEY 14/2007). Señalamos que como elemento diferenciador, solo hace especial referencia al emplazamiento geográfico, pero sus valores de protección, o sea "por su interés histórico, arqueológico, paleontológico, artístico, etnológico, industrial, científico, social o técnico" son los mismos que los de monumento.

El mismo concepto de inmueble encaja mejor con la idea de arquitectura, pero no funciona de igual manera con el propio hecho urbano de la calle, barrio o ciudad. Y menos aún cuando ésta es capaz de articular o es la razón de ser de todo un territorio.

Aunque para ser honestos hay que señalar que aunque explícitamente las leyes no indican para la tipología $\mathrm{CH}$ expresiones como formas de vida, cultura, actividades y modos de producción o vinculados a modos de extracción, producción, comercialización, transporte o equipamiento, o al valor de uso y disfrute para la colectividad y, en su caso, valores paisajísticos y ambientales, o la idea de conjunto patrimonial, diverso y complementario, en algunos de los ejemplos declarados en la Sierra de Cádiz, estas cuestiones se tienen en cuenta.

De esta etapa última son las declaraciones de Torre Alháquime, Ubrique, Grazalema y Bornos, así como la ampliación del $\mathrm{CH}$ de Arcos de la Frontera. En esta serie, encontramos por primera vez planos definitorios de las delimitaciones (plano 9) y, en el caso de Arcos, el único de los 10 $\mathrm{CH}$ de la Sierra que cuenta con entorno delimitado. En Arcos (DECRETO 105/2004) se señalan expresamente "(...) valores históricos, paisajísticos, urbanísticos, arquitectónicos y estéticos, así como enclave geográfico ha constituido en todos los tiempos un lugar estratégico. La protección de los valores histórico-artísticos, paisajísticos y estéticos, que sintetizan las particularidades del núcleo urbano, así como de las relaciones del Conjunto con su entorno (...)". 


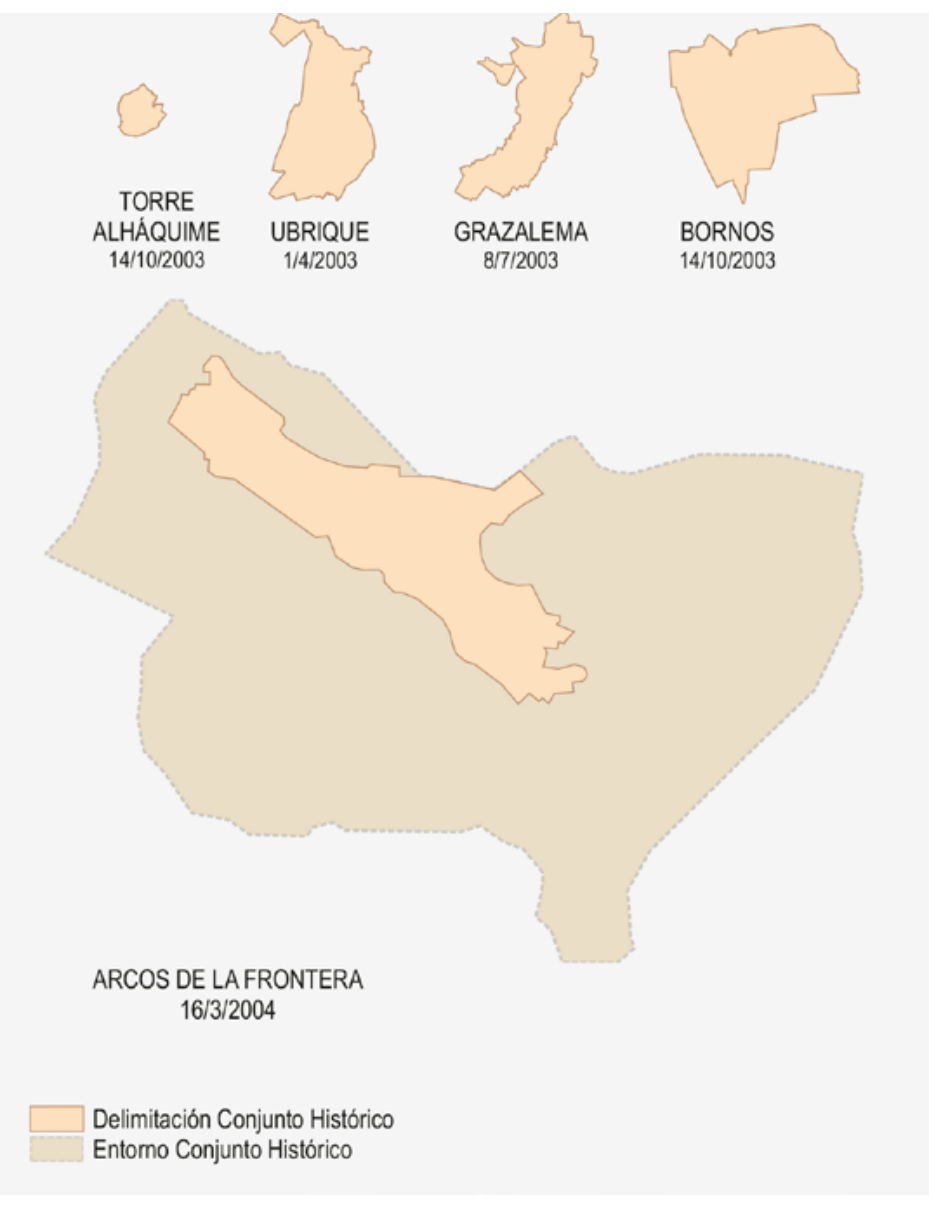

Finalmente nos planteamos qué sucede con los municipios que no han sido aún declarados. La definición de conjunto histórico no admite matices, se es o no se es. Esta situación que es una realidad legal general para todas las tipologías, no es del todo cierta pues, en el contexto de la gestión patrimonial urbanística, tipologías como la de monumento, admiten escalas de grises ya que puede escalonarse la protección en figuras intermedias, mediante el gradiente que nos proporciona la catalogación urbanística. En la tipología $\mathrm{CH}$ no existen categorías intermedias o inferiores. Esta carencia se intenta a veces solucionar, con el voluntarismo de la gestión administrativa, utilizando el concepto de entorno de bienes culturales de forma generosa, aprovechando alguna declaración en curso (plano 10). La idea de un "perímetro patrimonial básico" en situaciones intermedias podría favorecerse, al menos desde la redacción del planeamiento urbanístico.

Esta escala de grises, propicia lo que algunos autores denominamos la pirámide patrimonial ${ }^{10}$ de la protección, donde en la base se sitúan los bienes de menor relevancia y en la cima los bienes más excepcionales. ¿Cuál sería la de la Sierra de Cádiz? (plano 11).
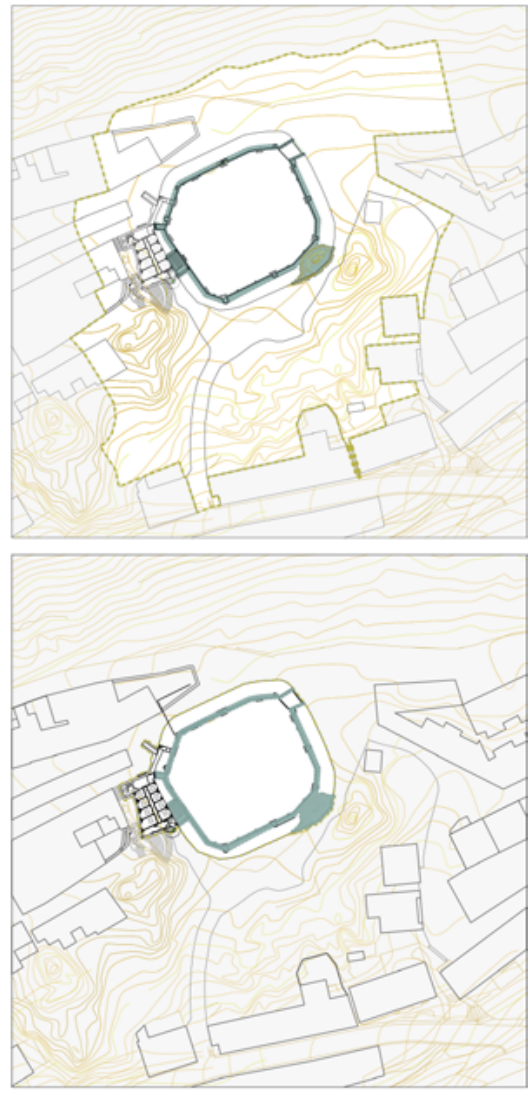

DELIMITACIÓN DEL BIC DELIMITACIÓN DEL ENTORNO DEL BIC

9. Conjuntos históricos cuya delimitación fue acompañada de la planimetría. Se han representado a la misma escala, para que se aprecie la gran diferencia de tamaño entre unos y otros | plano elaboración propia a partir de decretos declaratorios

10. Plaza de Toros de Villaluenga del Rosario Opciones de entornos estudiados en la realización del Expediente de Protección | plano base Hum 700. Imagen María Teresa Pérez Cano 
11. Municipios declarados conjunto histórico de la Sierra de Cádiz: 1. Arcos de la Frontera, 2. Olvera 3. Zahara de la Sierra, 4. Setenil de las Bodegas, 5. Benaocaz, 6. Algodonales, 7. Ubrique, 9. Grazalema 10. Bornos

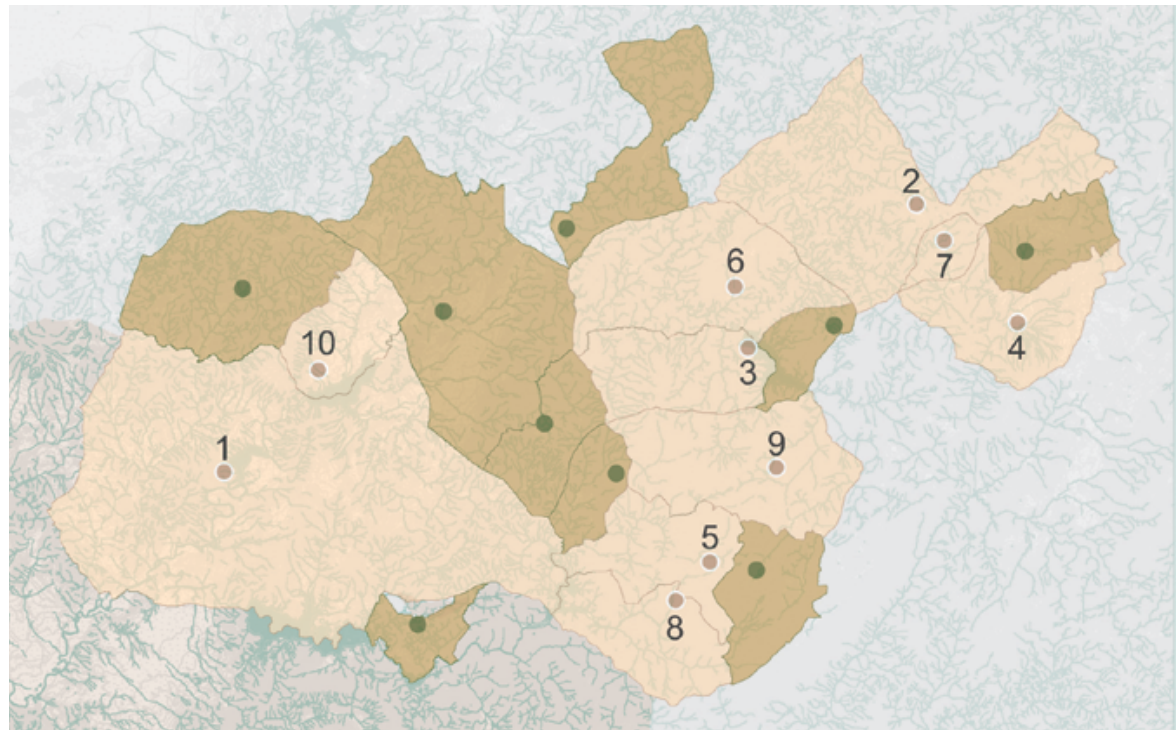

Villamartín es la tercera en población de la comarca, y la segunda en superficie, lo que siguiendo el criterio alegado en algunas declaraciones, sea el caso de Ubrique (DECRETO 91/2003) ' "(...) No obstante, la tensión constructiva de nuevas construcciones, derivadas del potente crecimiento económico de las últimas décadas, está empezando a alterar el perfil histórico que aún subsiste y que es necesario proteger (...)" corre cierto peligro. Conquistada en 1342, y reconquistada 1503, su pasado nos indica valores territoriales de frontera a considerar.

De lo que fuera provincia de Granada, destacan las inexplicables ausencias de Alcalá del Valle y Villaluenga del Rosario. En ambas podríamos encontrar características similares a las encontradas en Torre Alháquime "(...) conjunto con valor ambiental y adecuada escala de los espacios urbanos en relación con las construcciones. Su máximo interés se sustenta en los condicionantes físicos que han configurado su trama (...)" o Grazalema "La protección del legado histórico, artístico y particularmente etnológico, que ha mantenido una forma de vida basada en sistemas tradicionales, condicionado por su abrupta topográfica y por la distancia a cualquier núcleo de población importante, justifican plenamente su declaración como Bien de Interés Cultural (...)" (DECRETO 70/2003; DECRETO 208/2003).

Pero este acercamiento no sería completo si no se incluyesen propuestas para aquellos municipios que son ejemplo de nuevas fundaciones por repoblamiento, algunas cultas como Puerto Serrano (1615), y otras más recientes como El Bosque (1815) o El Gastor (1834) o incluso, la pedanía de Grazalema, Benamahoma insertada en la ruta de los Pueblos Blancos al igual que los diecinueve municipios analizados. En una etapa dónde la sostenibilidad forma parte del patrimonio, donde conceptos como el de resiliencia se va abriendo paso, pensamos que estos municipios merecerían otra consideración. 


\section{BIBLIOGRAFÍA}

- AA. VV. (2003) Territorio y patrimonio: los paisajes andaluces. Sevilla: Instituto Andaluz del Patrimonio Histórico, Consejería de Cultura, Junta de Andalucía, 2003 (Cuadernos; XV)

- AA. VV. (2002) Las Siete Villas de la Serranía de Villaluenga, 1502-2002. Frontera, repoblación señorial y patrimonio mancomunado en Andalucía. Ubrique, Cádiz: Fundación de las Siete Villas, 2002

- AA.VV. (2000) La Provincia de Cádiz, Pueblo a Pueblo. Cádiz: Industrias Gráficas Gaditanas, 2000

- AA.VV. (1994) Patrimonio y ciudad: reflexión sobre centros históricos. Sevilla: Instituto Andaluz del Patrimonio Histórico, Consejería de Cultura, Junta de Andalucía, 1994 (Cuadernos; V)

- BECERRA GARCíA, J. M. (2010) El patrimonio histórico y el planeamiento urbanístico en Andalucía. En El nuevo marco legal del patrimonio histórico andaluz. Sevilla: Instituto Andaluz de Administración Pública, 2010, pp. 3154

- DECRETO 91/2003, de 1 de abril, por el que se declara Bien de Interés Cultural, con la categoría de Conjunto Histórico, el sector delimitado a tal efecto de la población de Ubrique (Cádiz). Boletín Oficial de Estado, n. ${ }^{\circ} 133$, de 4 junio de 2013

- DECRETO 70/2003, de 11 de marzo, por el que se declara bien de interés cultural, con la categoría de conjunto histórico, el sector delimitado a tal efecto de la población de Torre Alháquime, en Cádiz. Boletín Oficial del Estado, n. ${ }^{\circ}$ 111, de 9 de mayo de 2003

- DECRETO 208/2003, de 8 de julio, por el que se declara bien de interés cultural, con la categoría de conjunto histórico, el sector delimitado a tal efecto de la población de Grazalema (Cádiz). Boletín Oficial del Estado, n. ${ }^{\circ} 230$, de 25 de septiembre de 2003

- DECRETO 105/2004, de 16 de marzo, por el que se amplía la delimitación del bien de interés cultural, con la categoría de conjunto histórico, de la población de Arcos de la Frontera (Cádiz), declarada Monumento HistóricoArtístico por Decreto que se cita. Boletín Oficial de la Junta de Andalucía, n. ${ }^{\circ}$ 74, de 16 de abril de 2004

- FARIÑA TOJo, J. (2000) La protección del patrimonio urbano. Instrumentos normativos. Madrid: Akal, 2000

- LEY de 13 de mayo de 1933 relativa al Patrimonio Artístico Nacional. Gaceta de Madrid, n. ${ }^{\circ}$ 145, 25 de mayo de 1933

- LEY 16/1985 de Patrimonio Histórico Español, de 25 de junio. Boletín Oficial de Estado, n. ${ }^{\circ} 155$, de 29 de junio de 1985
- LEY 14/2007 de Patrimonio Histórico de Andalucía, de 26 de noviembre. Boletín Oficial de la Junta de Andalucía, n. ${ }^{\circ} 248$ de 19 de diciembre de 2007

- LEY 1/1991 de Patrimonio Histórico de Andalucía, de 3 de julio. Boletín Oficial de la Junta de Andalucía, n. ${ }^{\circ} 59$ de 13 de julio de 1991

- MADOZ, P. (1986) Diccionario Geográfico-EstadísticoHistórico de Andalucía Cádiz. Valladolid; [Sevilla]: Ámbito: Ediciones Andaluzas Unidas, 1986 [Ed. facs.]

- PÉREZ CANO, M. T. (2015) Estrategias y retos en la docencia del patrimonio. La Dehesa. En Cuadernos de Transferencia Arquitectura y Patrimonio Histórico, HUM700US, Sevilla, 2015

- PÉREZ CANO, M. T. (2010) La protección del patrimonio desde el planeamiento urbanístico. III IAU I+D+I / 3.as Jornadas sobre Investigación en Arquitectura y Urbanismo, Madrid 17, 18 y 19 de junio de 2009, E.T.S.A., Universidad Politécnica de Madrid. Madrid: Mairea Libros, DL 2010

- PÉREZ CANO, M. T.; ESPINO HIDALGO, B. DEL; RAMILA ARJONA, R. (2013) Historic cities conservation throughout Cultural Heritage Laws: Andalusian Historic Areas. En $3^{\text {rd }}$ Annual International Conference on Architecture. 10-13 June 2013, Athens, Greece

- PLAN de Ordenación del Territorio de Andalucía, Decreto 206/2006 de 28 de noviembre. Boletín Oficial de la Junta de Andalucía, n. ${ }^{\circ}$ 250, de 29 de diciembre de 2006 